Award Number: DAMD17-03-C-0111

TITLE: Analytical and Characterization Studies of Organic Chemicals, Drugs and Drug Formulation

PRINCIPAL INVESTIGATOR: Peter Lim, Ph.D.

CONTRACTING ORGANIZATION: SRI International

Menlo Park, California 94025

REPORT DATE: October 2006

TYPE OF REPORT: Annual

PREPARED FOR: U.S. Army Medical Research and Materiel Command

Fort Detrick, Maryland 21702-5012

DISTRIBUTION STATEMENT: Approved for Public Release;

Distribution Unlimited

The views, opinions and/or findings contained in this report are those of the author(s) and should not be construed as an official Department of the Army position, policy or decision unless so designated by other documentation. 


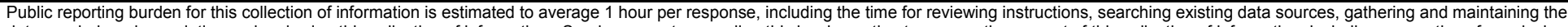

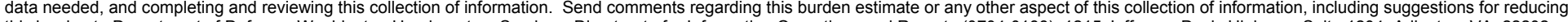

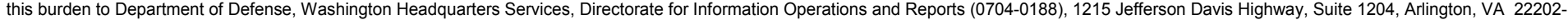

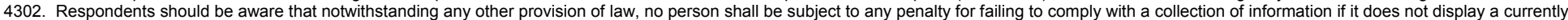
valid OMB control number. PLEASE DO NOT RETURN YOUR FORM TO THE ABOVE ADDRESS.
1. REPORT DATE (DD-MM-YYYY)
2. REPORT TYPE
3. DATES COVERED (From - To)

01-10-2006

Annual

4. TITLE AND SUBTITLE

22 Sep $2005-21$ Sep 2006

5a. CONTRACT NUMBER

Analytical and Characterization Studies of Organic Chemicals, Drugs and Drug

Formulation

DAMD17-03-C-0111

5b. GRANT NUMBER

5c. PROGRAM ELEMENT NUMBER

6. AUTHOR(S)

Peter Lim, Ph.D.

5d. PROJECT NUMBER

E-Mail: peter.lim@sri.com

5e. TASK NUMBER

7. PERFORMING ORGANIZATION NAME(S) AND ADDRESS(ES)

5f. WORK UNIT NUMBER

SRI International

Menlo Park, California 94025

8. PERFORMING ORGANIZATION REPORT NUMBER

9. SPONSORING I MONITORING AGENCY NAME(S) AND ADDRESS(ES)

10. SPONSOR/MONITOR'S ACRONYM(S)

U.S. Army Medical Research and Materiel Command

Fort Detrick, Maryland 21702-5012

11. SPONSOR/MONITOR'S REPORT NUMBER(S)

12. DISTRIBUTION I AVAILABILITY STATEMENT

Approved for Public Release; Distribution Unlimited

\section{SUPPLEMENTARY NOTES}

\section{ABSTRACT}

During the annual contract period, September 22, 2005 to September 21, 2006, the project personnel continued to perform chemical/physical analyses on bulk pharmaceutical substances and formulated drug products, and to develop and (with borrowed labor) manufacture dosage formulations of interest to the USAMRMC Drug Development Program for parasitic and infectious diseases, chemical and biological defense, etc. Specific objectives were to design, develop, validate, and apply methods to determine chemical and physical characteristics of the bulk drugs, drug products, and to determine their stability under defined conditions.

\section{SUBJECT TERMS}

Antiparasitic Drugs, Chemical Defense Agents, Chemical Analyses, Stability Studies, Formulation Development, Dosage Formulation Manufacture

\section{SECURITY CLASSIFICATION OF:}

a. REPORT

U b. ABSTRACT

U
17. LIMITATION OF ABSTRACT

c. THIS PAGE
U
18. NUMBER OF PAGES

10 19a. NAME OF RESPONSIBLE PERSON USAMRMC

19b. TELEPHONE NUMBER (include area code) 


\section{TABLE OF CONTENTS}

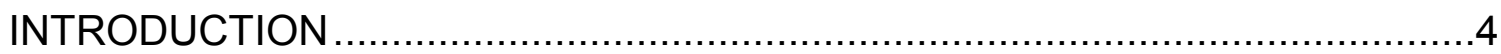

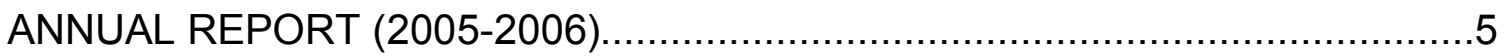

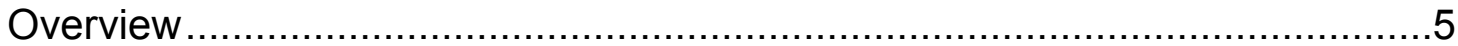

Specific Tasks Performed and Reports Submitted.....................................

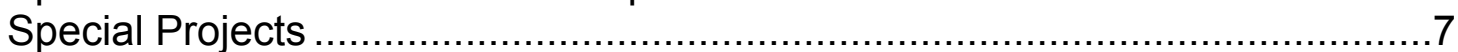

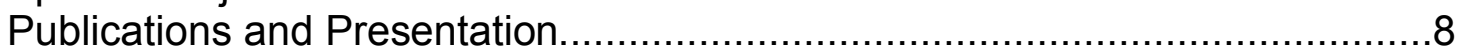

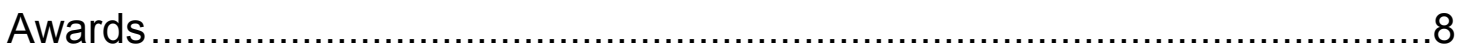

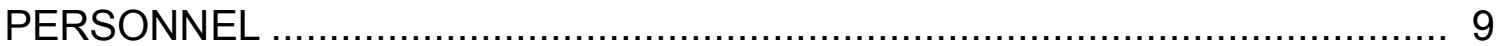

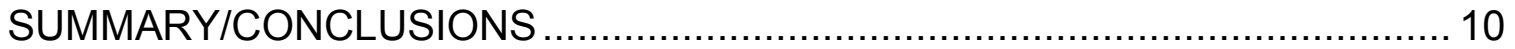




\section{INTRODUCTION}

This annual report for Contract DAMD17-03-C-0111 covers the period from September 22, 2005 - September 21, 2006. The report consists of an overview of the major activities, a listing of the specific tasks performed and reports submitted, and description of special projects carried out. The report also includes a listing of personnel receiving pay from this effort and a bibliography of all publications and meeting abstracts that resulted from this contract during the report period.

This contract is concerned with analytical, characterization, and stability studies of chemicals, drugs, and drug formulations, and with development and manufacture of dosage formulations. The studies are monitored by Mr. William Y. Ellis, the Contracting Officer Representative (COR), Chief, Department of Chemical Information, Division of Experimental Therapeutics, Walter Reed Army Institute of Research (WRAIR).

The overall objective of this project is the operation of an analytical laboratory to determine the identity, purity, strength, quality, physical and chemical properties, and stability of bulk pharmaceutical substances and formulated drug products, and to develop and manufacture, in limited quantities, dosage formulations of interest of the USAMRMC Drug Development Program for parasitic and infectious diseases, chemical and biological defense, anti-viral studies, etc. Specific objectives are to design, develop, validate, and execute methods to determine the following characteristics of candidate bulk pharmaceutical substances and formulated drugs, and to develop and manufacture, in limited quantities, dosage formulations.

- Identity, purity, and strength

- Stability

- Other physical and chemical characteristics, including weight variation, content uniformity, and other such compendial requirements

- Qualitative and quantitative determination of impurities

- Develop and manufacture, in limited quantities, dosage formulations

- Special projects not covered by the above headings. 


\section{ANNUAL REPORT (2005-2006)}

\section{OVERVIEW}

During the contract period September 22, 2005 to September 21, 2006, the emphasis of our project work continues to center on the need to maintain the SRI manufactured artesunic acid (AS) drug product acceptable for its ongoing clinical trials. During the first quarter of the contract period, stability results from drug units stored 12 months at $25^{\circ} \mathrm{C} / 60 \%$ relative humidity $(\mathrm{RH})$ failed the USP <788> test, particulate for injection. Had the clinical supply of the drug units stored at the Army's repository decomposed to the same or greater extent, the clinical supply would fail the USP $<788>$ requirements, and the failure would have halted the ongoing clinical trials. Fortunately, the clinical supply at the Army repository was stored at lower temperatures, $18-21^{\circ} \mathrm{C}$, over its storage duration. Drug units stored at these temperatures were pulled and analyzed. The results met the USP $<788>$ requirements but indicated higher particulate counts than those found at the time the product was released. The remainder of the $18-21^{\circ} \mathrm{C}$-stored clinical supply was immediately transferred to a freezer storage area maintained at $-20^{\circ} \mathrm{C}$ for at least the remainder of the clinical trials. To ensure the usable status of these freezer-stored drug units, a new stability protocol was written and a new stability study program commenced. Thus far, units pulled after six months storage at $-20^{\circ} \mathrm{C}$ have been able to meet the USP $<788>$ and other stability test requirements. When drug units are requisitioned and shipped from the $-20^{\circ} \mathrm{C}$ facility, they are stored temporarily in a refrigerator at a pharmacy until use. For this reason, a stability protocol for storage at $5^{\circ} \mathrm{C}$ was also written and its stability program also started.

The presence of excess dihydroartemisinin (DHA) in a drug unit is the primary cause for the unit failing the USP $<788>$. Studies on the formation of DHA and its relationship with particulates continue. Modifications to the USP $<788>$ sample preparation procedure tailored to slightly decomposed dosage units are ongoing.

When the SRI manufactured dosage units failed its accelerated stability study, six months storage at $40^{\circ} \mathrm{C} / 75 \% \mathrm{RH}$, units of the Guilin manufactured Artesunate For Injection (AFI) that had been stored at $4^{\circ} \mathrm{C}$ since receipt were placed in the same humidity chamber and identically stressed. Early results indicate that the AFI product is more stable than the SRI product under identical stress conditions. Meanwhile, comparative physical and chemical studies on the two drug products are ongoing, with the intent of finding a difference(s) that can account for the higher stability of the AFI product. 


\section{SPECIFIC TASKS PERFORMED AND REPORTS SUBMITTED}

During the contract period September 22, 2005 to September 21, 2006, the following tasks were performed and the reports submitted to the COR.

1. WR016506;BR29478, placebo for artesunic acid (AS), stability after 18 months storage at $25^{\circ} \mathrm{C} / 60 \% \mathrm{RH}$, Report 1148 .

2. WR135946;BR18064, sodium phosphate dissolution medium, Afton Scientific Batch 578-04, 12-month stability, Report 1138.

3. WR249309AP;BLI35711, artemisinin, characterization of a bulk chemical, Report 1147.

4. WR249943, shipment number $1137 \mathrm{PL}, \mathrm{MMB}-4-\mathrm{diCl}$, determination of chromatographic purity and bromide content, Report 1137.

5. WR253997AH;BM11609, dihydroartemisinin (DHA), characterizations of a bulk chemical and its two epimers, Report 1143.

6. WR256283, AS in Guilin Artesunate For Injection, characterization of constituted solution in sodium bicarbonate follow by dilution with $5 \%$ glucose, Report 1112-Revised.

7. WR256283;BQ37377, validation of a packed-column gas chromatographic method for the determination of ethylene oxide (EtO) in EtO-treated bulk AS, Report 1129. Investigations on relationship of particulate counts and DHA concentrations in solutions of AS in sodium phosphate were carried out, Report 1139. A study in changes in particulate counts with time in solutions of AS in the sodium phosphate dissolution medium was conducted, Report 1141. Twelve-months shelf-life stability study on AS bulk samples of BQ36281;BQ37377;BQ38641 has been completed, Report 1145. A 12-month shelf-life stability study on EtO-treated bulk AS was completed, Report 1146. A comparative study of room-temperature solubility of Knoll AS in phosphate and AFI in bicarbonate $/ 5 \%$ glucose has been carried out, Report 1144 . A detailed comparative solution stability on Knoll AS constituted in phosphate and in bicarbonate/glucose and on AFI constituted in the same media has been carried out, Report 1156, preliminary.

8. WR256283;BR29478, stability of Batch $14462-16$ AS units stored at the Army repository for 13 months at $18-21^{\circ} \mathrm{C}$, Report 1134 . Failure investigation on units of Batch $14462-16$ stored 12 months at $25^{\circ} \mathrm{C} / 60 \% \mathrm{RH}$ (shelf-life) has been carried out, Report 1135. Stability of Batch 14462-16 units stored 7 months at $18-21^{\circ} \mathrm{C}$ at the repository followed by storage at a clinic pharmacy for five (5) months at $\sim 26^{\circ} \mathrm{C}$ was determined, Report 1136. Failure 
investigation on Batch $1442-16$ units stored 12 months at $25^{\circ} \mathrm{C} / 60 \% \mathrm{RH}$ by QA/QC personnel was carried out, Report 1140. Development and application of a GC method to determine water vapor content in head space of sealed vials of AS was completed, Report 1142. Time zero $\left(T_{0}\right)$ data for a new stability study for samples to be stored at $-20^{\circ} \mathrm{C}$ and at $5^{\circ} \mathrm{C}$ were established, Report 1149. Official QA/QC report for above data was submitted, Report 1153.

9. WR256283;BR29478, permeation of moisture into sealed vials analogous to those of the AS clinical supply, Batch 14426-16, was determined, Report 1150. Investigation on the use of sterile filtration to salvage decomposed units of Batch 14426-16 was completed, Report 1151. A review of physical and chemical studies performed to improve stability of Batch 14426-16 was submitted, Report 1152.

10. WR288901;BR52744, characterization study, Report 1127.

\section{SPECIAL PROJECTS}

During this report period, we continue to refine the sample preparation portion of USP <788>, particulate in injections. Satisfying the requirements in USP <788> is paramount to the "life" of our AS drug product. The sample preparation step given in USP <788> is unsuitable for our drug product because our product dissolution medium, sodium phosphate, is a surfactant, which when agitated, forms bubbles that are counted as particulates.

The dissolution of AS in phosphate requires agitation of the mixture because the AS does not easily wet. Moreover, samples of AS that have undergone hydrolytic decomposition contain dihydroartemisinin (DHA), which, not only does not readily wet, but has very limited solubility in aqueous media, including phosphate. For hydrolytically decomposed AS samples, not only the dissolution time needs to be lengthened, but the bubble-dissipation time also has to be extended. Results from these studies suggest that such extensive changes to sample preparation are of value primarily for samples that are on the borderline of failure or pass. For samples that contain significant amounts of DHA, no practical sample preparation procedure will allow such samples to pass the USP $<788>$.

The need to employ our modified USP $<788>$ was well demonstrated when Afton Scientific Corporation (ASC), our contract manufacturer of the sodium phosphate dissolution medium, employed the published, standard USP $\langle 788\rangle$ to determine particulate in injection in order to release its product. The ASC results failed the USP requirements and the product could not be released. In our hands and using our modified sample preparation procedure, results from the ASC product 
easily met the USP particulate requirements, enabling the ASC product release. Analogously, in the hands of the SRI QC personnel who also employed the standard USP $<788>$, results from the AS constituted in phosphate failed the test. In our hands and using our modified sample preparation procedure, results from constituted AS solution easily met the USP requirement.

The second special project, which also required a great deal of time and effort, concerns the determinations of ethylene oxide (EtO) and its hydrolysis products in our EtO-treated AS. The sterilization of our bulk AS was performed by a contractor, whose responsibility included determinations of residual EtO and its hydrolysis products. The contractor made an attempt to fulfill this portion of its responsibility, but the attempt fell far short of the goal. Realizing the ultimate burden has to be ours, we developed, validated, applied our methods to determine the subject residues in the EtO-treated AS and applied our results to the existing regulatory requirements.

\section{PUBLICATIONS AND PRESENTATION}

A manuscript entitled "Enhancement an Analytical Method for the Determination of Squalene in Anthrax Vaccine Adsorbed Formulations" was submitted to the COR. Upon receipt of approval, it was submitted for publication in the Journal of Pharmaceutical and Biomedical Analysis.

A poster entitled "Characterization of MMB-4 Bulk Drug and Development of Its Dosage Formulation" was presented June 2006 at the 2006 US Army Medical Defense Bioscience Review.

\section{AWARDS}

No awards were received during the report period. 


\section{PERSONNEL}

A listing of personnel who received major contract support during the report period is as follows:

1. Peter Lim, P.I.

2. Ronald Spanggord, Assistant P.I.

3. Patrick Macauley, Chemist

4. Mindy Johnson, Chemist

5. Jennifer Wang, Chemist

6. Manjula Prasad, Chemist II

7. Tom Bregante, QC Supervisor

8. Esther Yau, QA Supervisor 


\section{SUMMARYICONCLUSIONS}

Our shelf-life stability study results on the SRI manufactured artesunic acid (AS) dosage form indicate the drug product would be no longer acceptable for its ongoing clinical trials. Fortunately, the clinical supply of the drug product was stored under less-stressful conditions, and analysis on units thus stored showed results that enable the product to continue its clinical trials. Although these clinical supply units were found acceptable for the ongoing clinical trials, the AS in them has undergone measurable decomposition. To halt or minimize further decomposition, the clinical supply has been transferred from +18 to $+21^{\circ} \mathrm{C}$ to $20^{\circ} \mathrm{C}$ storage; to ensure the supply will remain acceptable for the ongoing clinical trials, a new stability study program has been initiated and is continuing.

To gain insight on the "unexpected" instability of the AS in the SRI drug product, units of the Guilin Artesunate for Injection drug product were analogously stressed and found to be more stable. Detailed comparisons of chemical/physical properties of the two AS drug products have been made; no definitive difference has been found that could explain the stability difference.

Owing to the very limited aqueous solubility of dihydroartemisinin (DHA), the amount of AS decomposition (hydrolysis) can be very little and the unit would fail the USP <788>. A simple filtration procedure has been developed that would remove all the particulates in the constituted AS solution and enable the clear filtrate to meet the USP $<788>$ and the label dose requirements.

Efforts unrelated to artesunic acid include studies on pyridiniumaldoximes. 